\title{
INTRODUCTION TO THE ISSUE
}

\section{Water in Southeast Asia: Navigating Contradictions}

\section{Lindsay Lloyd-Smith and Eric Tagliacozzo}

W ATER IS A CONSTANT theme in Southeast Asian scholarship, and while there have been several theme-specific edited volumes addressing the centrality of water in Southeast Asian societies both past and present (Boomgaard 2007; Rigg 1992; see also the edited volume by Boomgaard et al. 2005 concerning riverine and marine resources), none have sought to deeply cross thematic and disciplinary boundaries. This is somewhat surprising when one considers the ambiguous nature of water (in both real and abstract form) in Southeast Asian history, politics, economies, cultures, and religions. Unifying the maritime region and cutting across diverse landscapes, water offers an apt theme for the journal Trans -Regional and-National Studies of Southeast Asia to consider. At the same time, 'water' as a concept holds within it inherent contradictions. While it is often said of Southeast Asia that the 'seas unite and the land divides', one only needs to consider the ongoing international dispute of the South China Sea to see that this isn't necessarily so. This tussle threatens not only bilateral national relationships, but also - and perhaps more significantly the credibility of ASEAN as an international body itself, especially via the centrality of the 'waterscape' in defining geopolitical and socio-geographical perspectives of the region today. However, water in Southeast Asia - both fresh water of rivers and lakes, and salt water of the seas - is and has always been more than just a medium of surface transportation for trade and movement of people, or a source for material resources. Water is also a substantive and symbolic metaphor through which to frame conceptions and perceptions of human identity, and of the world itself.

Water plays transformative roles in many Southeast Asian socio-cultural and religious contexts, from the importance of daily bathing, to the (in some instances) cleansing, and (in others instances) polluting nature of water in its different forms (here we can think usefully of fresh as opposed to polluted water; sea water; rain water, etc.). As such, the theme of water naturally invites trans-disciplinary research that problematises the topic in new ways, while also seeking out the 


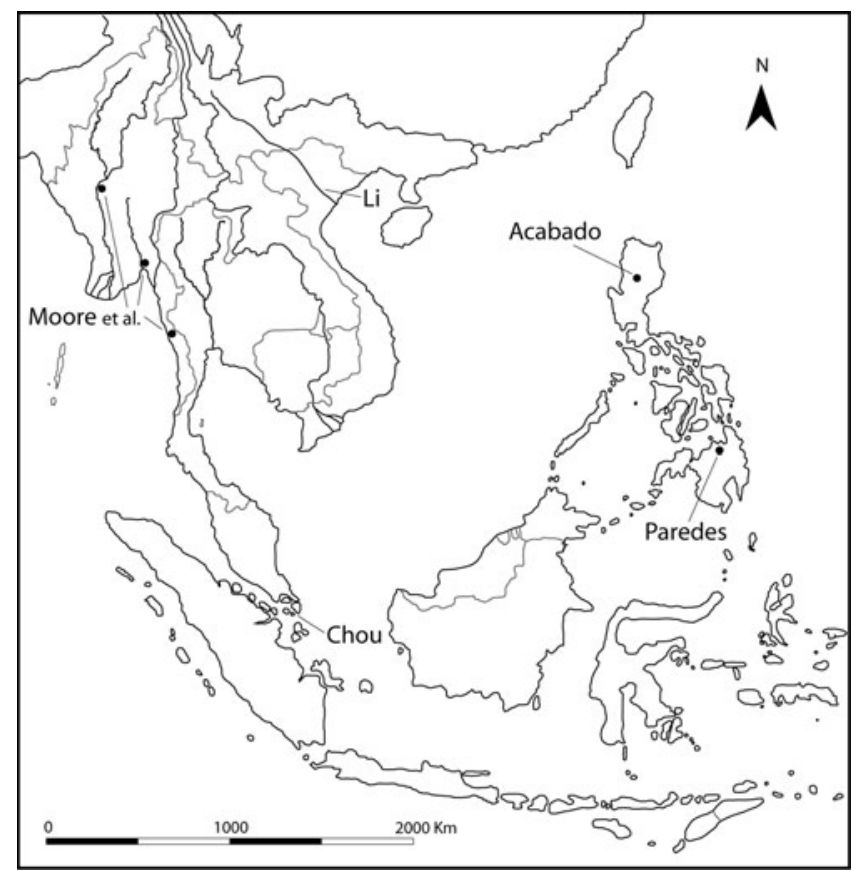

Figure 1. Map of Southeast Asia indicating the geographical focus of each article. (Illustration: L. Lloyd-Smith)

multiple and contradictory aspects of this essential, but not essentialising, substance. Because Southeast Asia is one of the wettest regions of the planet, with a monsoon climate and large amounts of rainfall every year, this seems like a perfect landscape to think through such relationships. The fact that half of Southeast Asia is maritime in nature, too, also presents useful opportunities in exploring overall themes. As a conduit-region between other parts of Asia, notably South and East Asia, these "lands below the winds" (Reid 1988, 1993) also take on larger complexities in the transmission of ideas, material, and people across wide open spaces. Such a reconceptualization of the place of water in Southeast Asia along a number of rubrics, therefore, seems somewhat overdue.

The articles collected in this issue of TRaNS - Water in Southeast Asia: Navigating Contradiction - derive from a small conference of the same name, organised by the Institute of East Asian Studies at Sogang University, 26-27 June 2014 (Figure 1). Remarking that although water is such a conspicuous element in shaping Southeast Asian history - through political, economic, and not least religious dimensions - Barbara Andaya notes that it is therefore surprising how little comparative analysis on the topic has been made. In her lead article that points the way for the general tenor of this special issue, Andaya sets out an impressive array of historical, anthropological, and ethnographic sources which show the potential wealth of data relating to the centrality of religious and spiritual beliefs concerning water across Southeast Asia. One reason Andaya offers for the apparent lack of comparative studies focused on the religious significance 
of water in Southeast Asia, is the fact that although it exists as a free-flowing liquid (think here of rain, springs, pools, rivers, deltas, seas, and oceans), the spirits that were believed to inhabit watery places were tied to local - and often very specific places: rapids, pools, stretches of coast, etc. (for example the water serpent Naga spirits; Figure 2). Therefore, the ontology of water as an element might be ephemeral, or in flux, but the meanings attached to the liquid were often grounded in very local contexts. A pool of water here might be considered salubrious, or even sacred; just down the road another collection of the substance might be deemed just the opposite. The fact that both places are formed by water and might be joined through rain or mist or evaporation seemed not to strike home to most Southeast Asians; a 'separate-ness' can be discerned in many of these evaluations. This was not always the case, but it was often enough true in various parts of traditional Southeast Asia that the notion does seem to hold currency along the width and breadth of the region for quite some time.

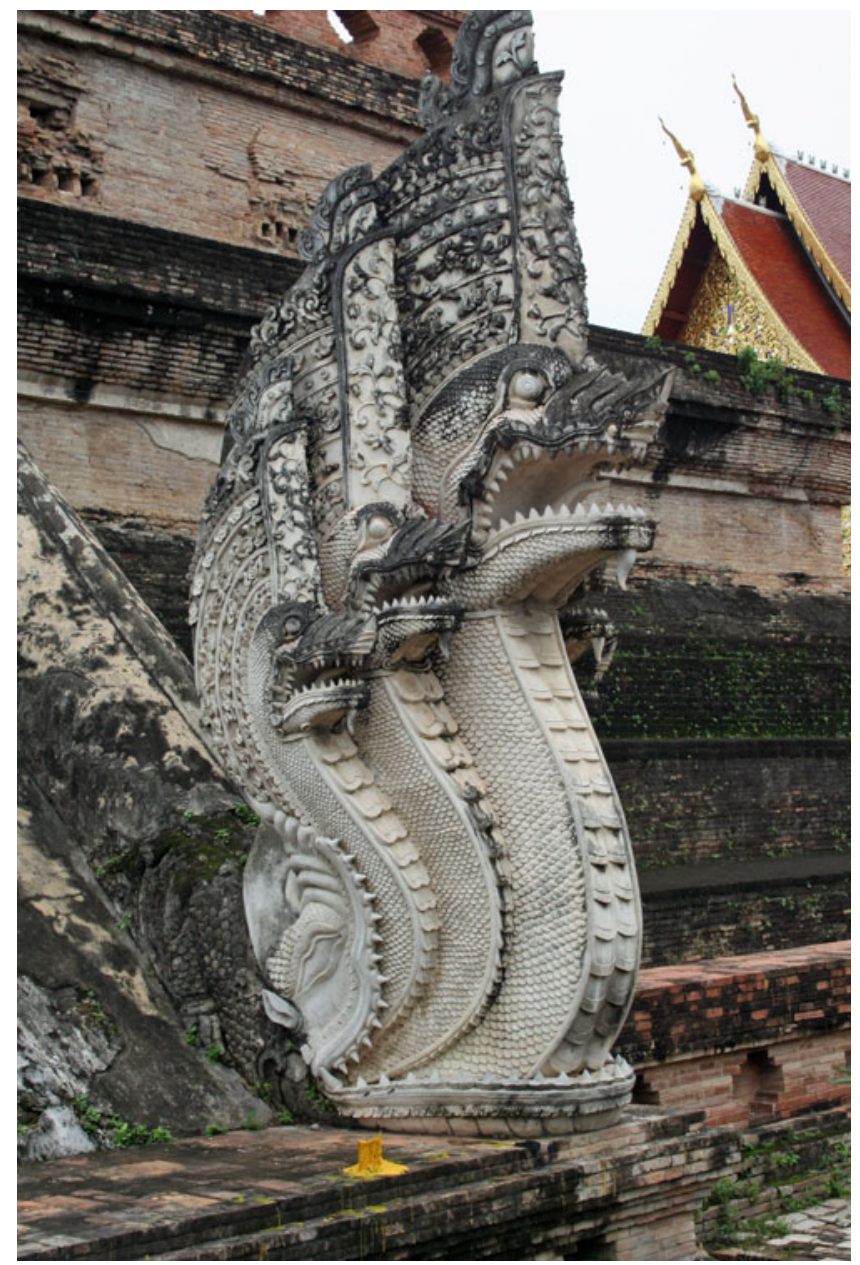

Figure 2. Naga balustrade, Wat Chedi Luang, Chiang Mai, Thailand. (Photograph: P. Lavy) 
A key point that comes out of Andaya's survey of literature pertaining to water spirits of Southeast Asia is that their inherent specificity can itself be an important object for study, particularly when viewed in terms of wider waterscapes, and inquiry into religious change and the adoption of world religions. Andaya's crucial observation is that while local spirits of watery places were often fickle either in benevolent or malevolent ways - local knowledge was essential if they were to be successfully placated. The rise of open-sea shipping during the early modern period was in many ways mentally facilitated by the adoption by seafarers of "portable" forms of compassionate water spirits (deities), who could then be identified in any port of call. Water, ideas of 'place', and a mental ability to transgress local specificities were thus fundamental elements in the successive widespread adoption, and adaption, of world religions to the diverse Southeast Asia context. This happened all the way across Southeast Asia, from Arakan and the marches of South Asia all the way out to New Guinea and the cultural borders of Oceania. It also happened all along the coast of mainland Southeast Asia in various societies, so this was not a culture syndrome predominantly associated with the maritime worlds of insular Southeast Asia only. Andaya therefore highlights the crucial importance of "locally grounded knowledge" in being able to navigate, both practically and ritually, the myriad fickle spirits which were once believed to inhabit every different part of the region's waterscapes. This paradigm held true from springs, pools, and rapids even to slow-moving rivers, the coasts, and ultimately out to the open sea.

In this light, perhaps the community best equipped to deal with the waterworld has been the dispersed groups of Orang Laut, or 'Sea Nomads', who traditionally spent the vast majority of their lives living on the ocean (Figure 3). The socio-ecological perception of one group of Sea Nomads - the Orang Suku Laut - is the focus of Cynthia Chou's article. Chou offers us detailed ethnographic descriptions of three key rites-of-passage of the individual into this community birth, naming, and the "sensory education derived from learning by living" in the Orang Suku Laut maritime water world. Chou describes how "the water world [of the Orang Suku Laut] is about engagement and not imposition, about dwelling and not building, and about embracing a view in it, rather than formulating a view." To be safely born into this world, the Orang Suku Laut must be aligned with the rising and falling of the tides. Personal names are taken from immediate aspects of their aquatic surroundings, and their kinetic and mnemonic learning of the waterworld is one where the "boundaries between self and other, as well as persons and objects, completely disappear." According to Chou, this is a wholly different way of being in the world, in many respects, from those of us who live a life on land. This is also a manner of going through one's existence which is completely and utterly predicated on one's maritime environment, as opposed to the more terrestrial concerns that most of us have about territory, nation-states, and boundaries. This is, however, a world under threat, as the norms and practices of the Orang Suku Laut come under increasing pressure from sedentarization and the policies of those 


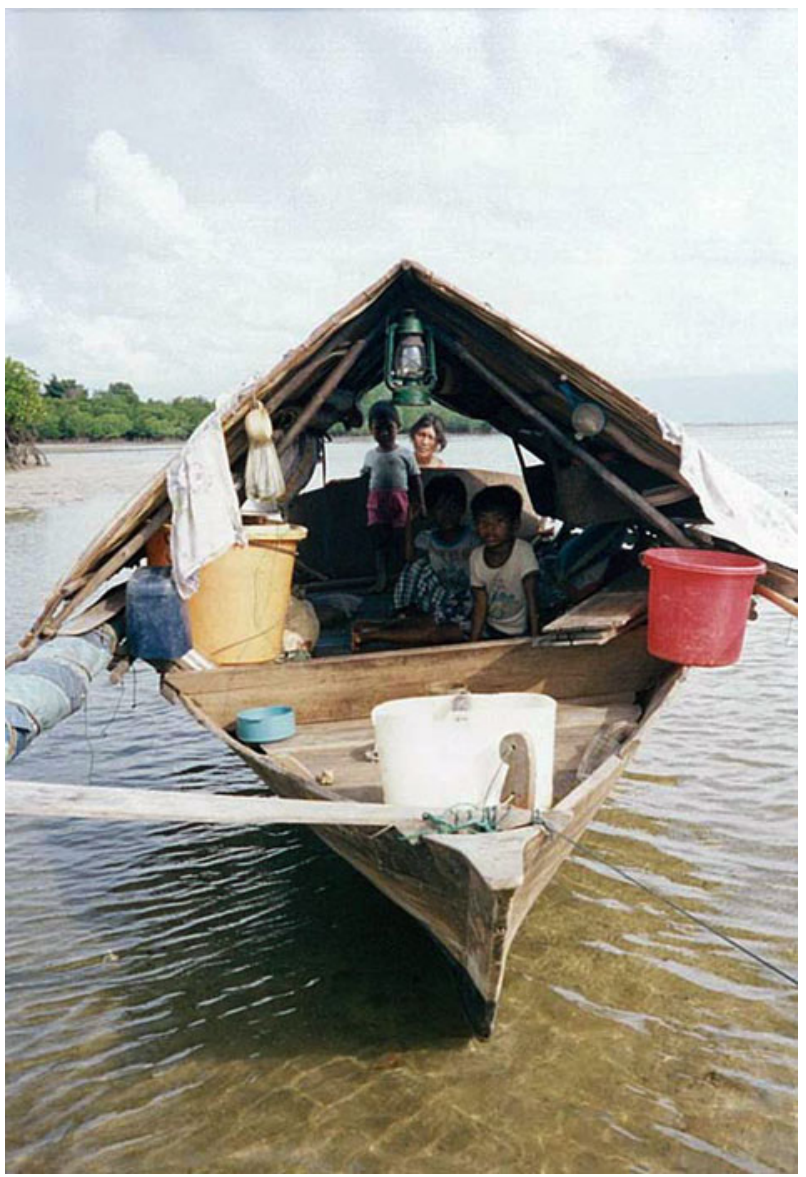

Figure 3. An Orang Suku Laut house boat. (Photograph: C. Chou)

same nation-states who see their free-flowing existence as a potential danger to government control.

In contrast to Chou's article, Moore, Win, and Kyaw focus not only on water on land - via early urbanised sites in Myanmar - but its management from a purely practical and pragmatic perspective. New data from recent archaeological surveys and excavation in Myanmar contrasts against the better-known research of ancient sites in Thailand and Cambodia, revealing, as Moore et al. note, much smaller transformations of the landscape with regard to the management of water in ancient Myanmar, but by no means less effective ones. What the new data confirms is that highly varied and localised water management systems developed in each area of Southeast Asia; local knowledge applied to find solutions sensitive to local ecological, and no doubt social, systems (and here this is reminiscent of Andaya's "locally ground knowledge" that was required to navigate vis-a-vis the spiritual waterscape). Though locally specific, on a larger scale sub-regional aspects of water are apparent. The three case studies of early historic sites in Myanmar are ecologically distinct - scattered across the high-rainfall area of 


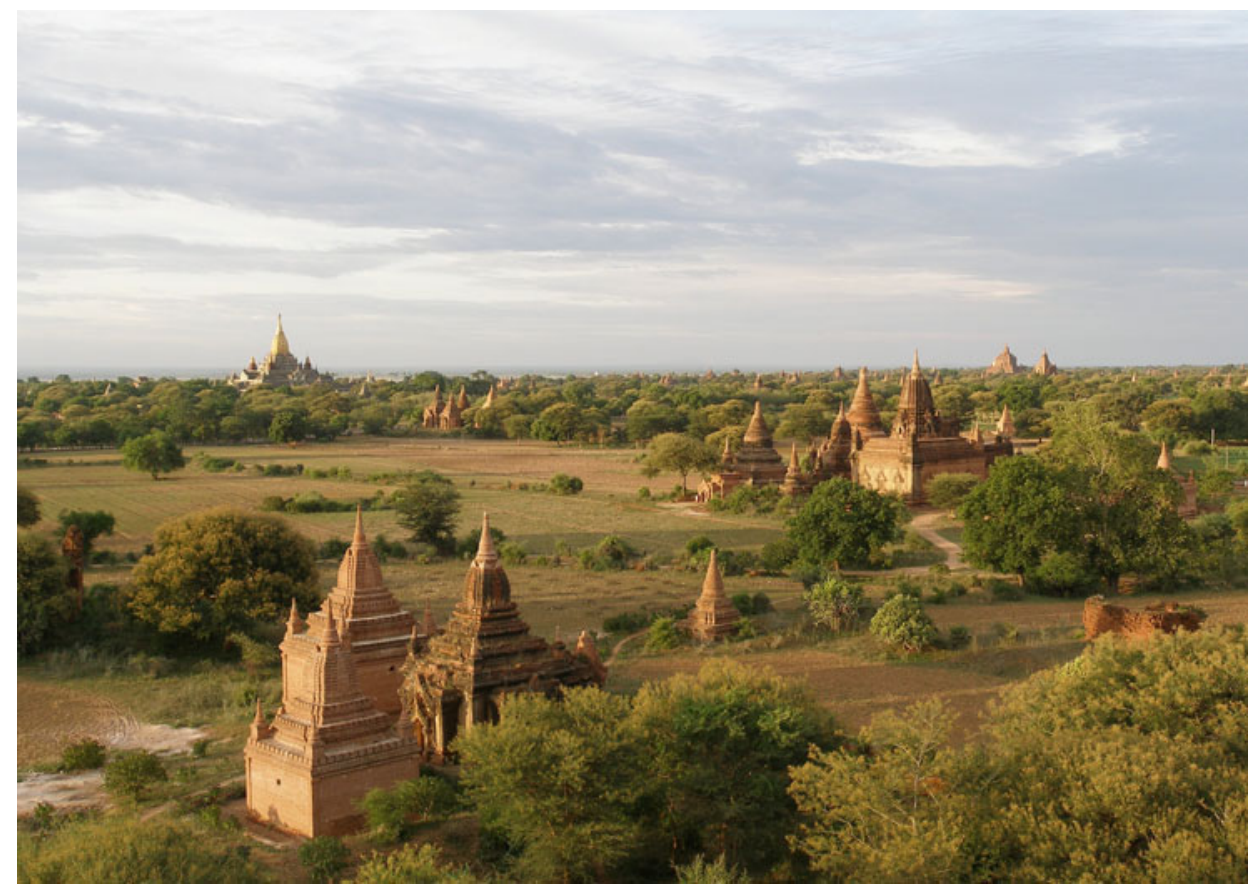

Figure 4. Bagan temples with the Irrawaddy River in background. (Photograph: Gusjer $)^{1}$

Lower Myanmar and the water-scarce region of Bagan in the arid zone of upper Myanmar (Figure 4) - yet they all shared a common feature of being located adjacent to rivers, but utilising these waterways for little else other than transportation. Instead, Moore et al. tell us, a characteristic of water management here was its "intricate, but small scale, diversions [of small tributaries], exploitation of ponds and lakes, and the strategic siting of temples." Classical Burma, in other words, worked out a water dependent schema that was not lock-in-step with models existing on the rest of the Southeast Asian mainland during the pre-modern period. As Myanmar continues the opening-up process in the coming decades (as it certainly looks like it will), there will no doubt be further refinements to these early conclusions, also supported by archaeological and geo-physical surveying.

Stephen Acabado and Marlon Martin continues the theme of land-based water management with their study of the Ifuago community of the Cordillera Central, northern Luzon (Figure 5). Famous for their spectacular terraced hill sides for wet-rice cultivation, recent research led by Acabado has overturned the orthodox 'old history' model for this stunningly-transformed landscape which had proposed that Ifugao settlement in the highlands dates back three thousand years. Instead, and making good use of archaeological data, he argues for a 'short chronology' of only four to five hundred years; the

${ }^{1}$ Image source: https://www.flickr.com/photos/gusjer/2414625530/; reproduced in accordance with Creative Commons License 2.0 (https://creativecommons.org/licenses/by/2.0/) 


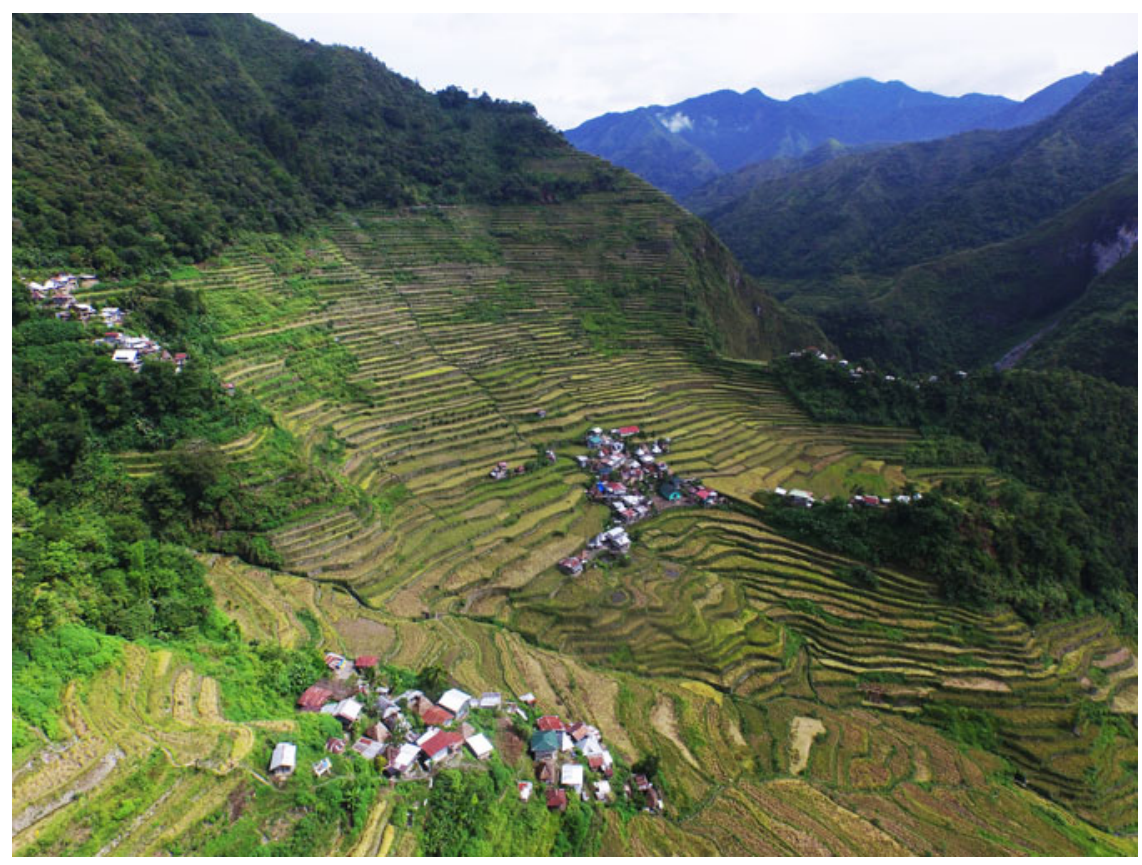

Figure 5. Rice terraces at Batad, northern Luzon. (Photograph: S. Acabado)

intensification of terrace building being the result of an inland population migration to avoid Spanish colonisation. Population pressure, according to Acabado, necessitated a shift to, and intensification of, wet-rice cultivation. This process transformed and, in many respects, produced the classic Ifugao "agro-cultural" system that we see today. What is interesting from the perspective of "sacred and secular" perceptions, and also from the management of water in this dramatic highland environment, is that it appears to have grown out of and transformed a pre-existing wet-cultivation system of taro. The higher population densities that wet-rice cultivation can support led to the emergence of a self-regulating 'Complex Adaptive System' in which "water and agricultural rituals in Ifugao [are] a cultural strategy to regulate activities that are detrimental to community cooperation". As such, "the sacred and the secular intersect in Ifuago water and agricultural systems", a case with broad similarities to that of the Balinese subak system. Yet as Acabado points out, water should not be seen as an essentialising component, as the "social organisation of the Ifugao differs remarkably from the Balinese." Still, the parallels are fascinating, from a comparativist/archaeological point of view. Water and its channels and flows allow us to make these comparisons.

In her article, the anthropologist Oona Paredes brings the topic full circle by analysing the metaphorical perceptions of the water-catchment systems of genealogical and politic descent of the indigenous, inland, Higaumon Lumad community on the island of Mindanao (Figure 6). She juxtaposes these systems with the ways in which the Lumad perceive the immigrant Filipino communities who now 


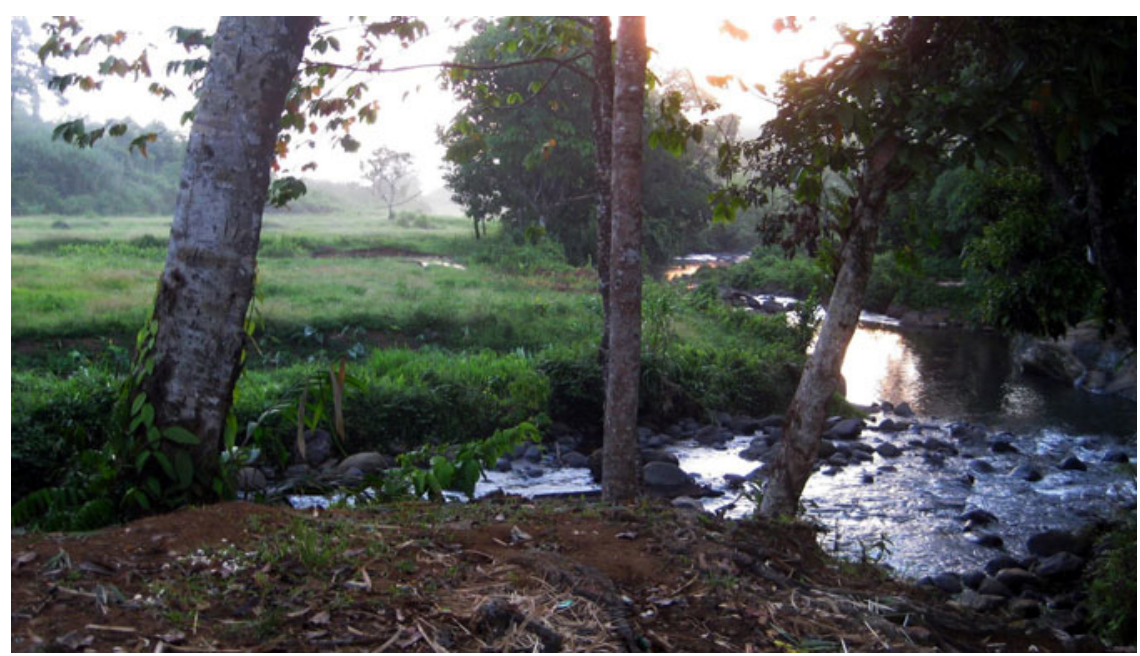

Figure 6. The Baligiyan River in northern Mindanao forming the border area between Misamis Oriental, Agusan del Norte, and Agusan del Sur provinces, Philippines. More importantly, this part of the river flows through the middle of the Baliguihan ancestral domain. (Photograph: O. Paredes)

mostly occupy the lowland and coastal areas. For the Higaumon Lumad, though they are an inland community, their socio-political world is spatially and temporally organised and conceptualised along water catchment lines, where "proximity to water often equated with degree of civilisation and purity [of the blood line]". From this (fresh) water perspective, the Higaumon Lumad view the Filipino settlers, referred to as dumagat ('sea-people'), are "interlopers at, or more often, beyond the moral boundaries of the Lumad universe." They occupy a whollyother strata of existence, in traditional Lumad norms, and one that can be diametrically-opposed to the Lumad's own. Although water as a significant medium or metaphor for categorisation and identification might not seem the most obvious or apparent way of understanding the inland Lumad community (Paredes in fact initially remarks, the "Higaumon will tell you that water is just water - inert and formless in the literal and figurative sense"), upon closer consideration of underlying conceptual spaces, water is "a key hermeneutic that configures the broader Higaumon worldview...[which] more than any other element transports [the community] along time and space, encapsulates their historicity and moral boundaries, and plays a profound and often transformative role in their identity and their oral traditions." In this appraisal, Paredes sees the seeds of Lumad originality, and also of Lumad singularity. Yet in keeping with the rest of the contributions here, we can see them in fact as part of a spectrum of Southeast Asian societies who exist across a connected arc of land and sea, yet who all make use of water in symbolically-crucial ways to order their own particular life-worlds.

Finally, the historian Li Tana concludes this collection of articles with an historical sketch of the Red River delta in northern Vietnam (Figure 7). Her short 


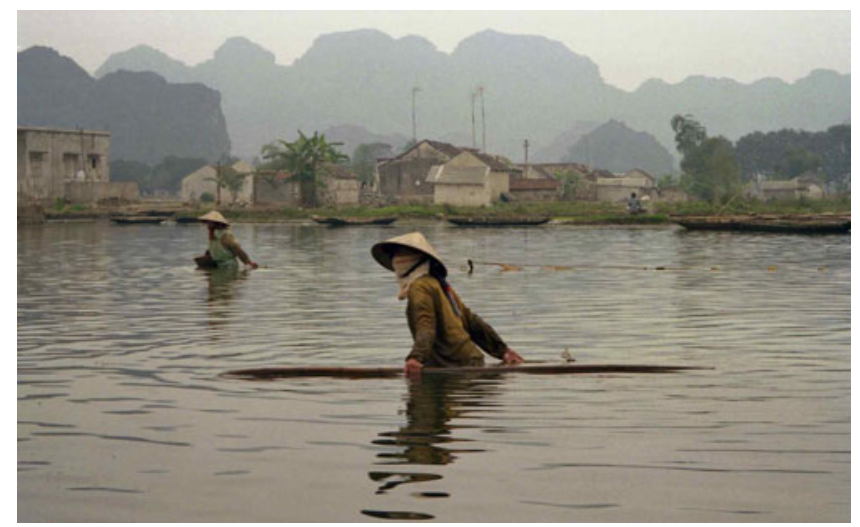

Figure 7. A deltaic tributary of the Red River, Hoa Lu, Ha Nam Ninh Province. (Photograph: Lon \& Queta) ${ }^{2}$

summary brings to the fore the two crucial aspects of time and space for contextualising an understanding of the significance of how water fundamentally shapes the flow of history. Rivers cut across geographical boundaries of geology while forming a unifying current joining different social groups. Actions upstream have repercussions in the river's lower reaches. The Red River has changed its course significantly over time and the delta has spread. These riparian shifts lie at the heart of understanding the historical origins of the city of Hanoi which, like a dragon, emerged out from the waters.

It would be difficult to find a more unifying theme than water in discussing attributes of organisation and connection among Southeast Asian societies, both historically and today. This notion has not gone un-noticed in the social-scientific literature, but it is a thought that has not been as well-developed as it might be, considering the overwhelming importance of water to Southeast Asian societies. The five research articles and one historical sketch presented in this special issue of TRaNS offer six very different perspectives on the theme of water in Southeast Asia. However, common themes do flow through them all. All the articles consider, in different ways, Southeast Asian societies' direct and explicit engagement(s) with 'water', both as a physical substance and/or as an abstract concept. These engagements serve dual purposes. On the one hand they form systems of water 'management' through which Southeast Asian societies navigate risk, both real and/or imagined, be that to secure, regulate, and control the supply of water (Moore et al.; Acabado and Martin; Li Tana); avoid excess water and flooding (Moore et al.); or supplicate the fickle 'watery' forces/spirits of nature, which often claim the lives of people living close to, or traveling over, water (Andaya). At the same time, in all the above-discussed examples, these engagements with water contribute significantly to the construction of individual and group (of one's own, and the

${ }^{2}$ Image source: https://www.flickr.com/photos/lonqueta/4008934960/ reproduced in accordance with Creative Commons License 2.0 (https://creativecommons.org/licenses/by/2.0/) 
'other') identity(ies), and respective 'places' in the world (most explicitly Andaya; Chou; Paredes; and - implicitly, Moore et al.; Acabado and Martin; Li Tana). By these processes, and through reflecting upon the meaning and management of 'water' in Southeast Asia, 'water' becomes a medium and metaphor for navigating social relations. This happens both within and between communities. It is no exaggeration, therefore, to say that waterscapes, both real and imaginary, are integral to Southeast Asian identity-formation, and to 'being in the world'. They help order the multiple universes of Southeast Asian societies in ways that are seen through the passage of time, and also in ways that we clearly can still see today.

\section{References}

Boomgaard, Peter, Henley, David and Manon Osseweijer (eds.). 2005. Muddied Waters: Historical and Contemporary Perspectives on Management of Forests and Fisheries in Island Southeast Asia. Leiden: KITLV Press.

Boomgaard, Peter. (ed.). 2007. A World of Water: Rain, Rivers and Seas in Southeast Asian Histories. Leiden: KITLV Press.

Reid, Anthony. 1988. Southeast Asia in the Age of Commerce. Volume 1: The lands below the winds. New Haven: Yale University Press.

Reid, Anthony. 1993. Southeast Asia in the Age of Commerce. Volume 2: Expansion and crisis. New Haven: Yale University Press.

Rigg, Jonathan (ed.). 1992. The Gift of Water: Water Management, Cosmology and the State in South East Asia. London: School of Oriental and African Studies. 